Artigo Original Original Article Artículo Original

Artigo Especial Special Article Artículo Especial

\title{
O médico veterinário e o comércio de peixes ornamentais
}

\section{The veterinarian and the commercial ornamental fish trading}

\section{El veterinario y el mercado de peces ornamentales}

\section{Ana Paula de Araújo; ${ }^{1}$ Agar Costa Alexandrino de Pérez²}

Instituto da Pesca da Secretaria de Agricultura e Abastecimento do Estado de São Paulo. São Paulo, SP, Brasil

\section{Resumo}

O presente trabalho tem como finalidade oferecer informações para o médico veterinário sobre o comércio e manejo de peixes ornamentais, uma área de atuação pouco abordada pelas faculdades de Medicina Veterinária e cursos de pósgraduação. O comércio de peixes ornamentais é uma atividade bem estabelecida no Brasil. Entretanto, carece de profissionais atuando em questões como manejo profilático, patologia, diagnóstico e tratamento. Também abrange novos conceitos para o médico veterinário, como os representados pelas propriedades físicas e químicas da água. $\mathrm{O}$ artigo aborda, de maneira sucinta, os principais pontos dessa atividade, os quais devem ser observados sob a ótica da Medicina Veterinária.

Palavras-chave: Peixes ornamentais. Comércio, organização e administração. Ambiente aquático fechado. Médicos veterinários. 


\section{Introdução}

O presente trabalho não pretende ser uma revisão, mas refere-se, muito mais, à vivência dos profissionais dentro da atividade de comercialização de peixes ornamentais. Em virtude de nossa experiência, sentimos-nos no dever de transmiti-la e facilitar os caminhos que terão que ser percorridos pelos colegas que pretendem atuar nesta área, uma vez que informações pertinentes são escassas ou ausentes na bibliografia especializada. O gerenciamento de estabelecimentos de manutenção e comercialização de peixes ornamentais é uma atividade muito interessante, que leva o profissional a buscar outros conhecimentos e conceitos. O aquarismo é um hobby relativamente difundido e bem-sucedido, no qual cães e gatos são substituídos por belíssimos animais aquáticos. Alexandrino ${ }^{1}$ (1999) alerta para a necessidade de preparar os profissionais médicos veterinários para atuar nesta atividade, que carece de medidas sanitárias, principalmente profiláticas.

No presente trabalho procura-se seguir uma seqüência de pontos importantes que devem ser observados dentro desse tipo de estabelecimento. Iniciase com os caminhos de comercialização dos peixes ornamentais, regulamentação do estabelecimento nos órgãos competentes e as informações sobre a qualidade da água (origem, filtragem, principais parâmetros). Segue-se, então, com o recebimento de animais no estabelecimento (triagem, aclimatação), manejo, principais doenças, além de uma abordagem sobre a segurança do funcionário que trabalha no local quanto às zoonoses, acidentes e manutenção de equipamentos. ${ }^{2}$

$\mathrm{O}$ assunto é muito amplo e as informações aqui descritas são dirigidas ao profissional, que terá a oportunidade de conhecer os principais passos para iniciar-se nesta atividade.

\section{Aspectos Gerais da Atividade}

\section{Legislação e regulamentação dos estabelecimentos junto aos órgãos competentes}

Este ponto é fundamental para que o profissional e o estabelecimento trabalhem de modo confortável dentro da legislação existente. Se hoje muitos estabelecimentos atuam de maneira deficiente no que diz respeito à regulamentação, acredita-se não ser por negligência, e sim, pela falta de orientação e pelo fato de que, até o momento, existem poucos profissionais habilitados para atuar nesta área.

Assim, um estabelecimento que comercializa peixes ornamentais deve ser registrado nos seguintes órgãos: Instituto Brasileiro de Meio Ambiente (IBAMA), Secretaria Especial de Aqüicultura e Pesca (SEAP), Ministério da Agricultura, Pecuária e Abastecimento (MAPA) e Conselho Regional de Medicina Veterinária (CRMV). Esses registros têm a finalidade de atender à legislação pertinente à cada órgão. Dessa forma, os estabelecimentos poderão trabalhar futuramente num nível mais elevado de segurança para seus negócios.

Por ser o Brasil país membro da Organização das Nações Unidas para a Agricultura e Alimentação (FAO), o Ministério da Agricultura, Pecuária e Abastecimento (MAPA) segue as diretrizes do Escritório Internacional de Epizootias (OIE) como fonte de informação sobre manejo profilático, trânsito internacional de animais, doenças de notificação obrigatória e estado sanitário dos outros países membros. Dessa maneira, o profissional que atua junto a empresas importadoras deve estar atualizado quanto às informações sanitárias referentes ao comércio internacional de animais aquáticos.

\section{Cadeia de comercialização}

A dinâmica do comércio de peixes ornamentais pode ser observada no organograma apresentado pela Figura 1, cujo modelo de comercialização ocorre da mesma forma no Brasil e no exterior. Todos os pontos percorridos pelos animais dentro desse organograma podem representar riscos sanitários para a atividade. Há, portanto, necessidade de o profissional conhecer todos os trâmites relacionados à aquisição desses animais. Esse conhecimento visa evitar a entrada de doenças, a disseminação de patógenos e, no caso de 
exportação, elevar o status sanitário dos animais, conquistando, assim, novos mercados.

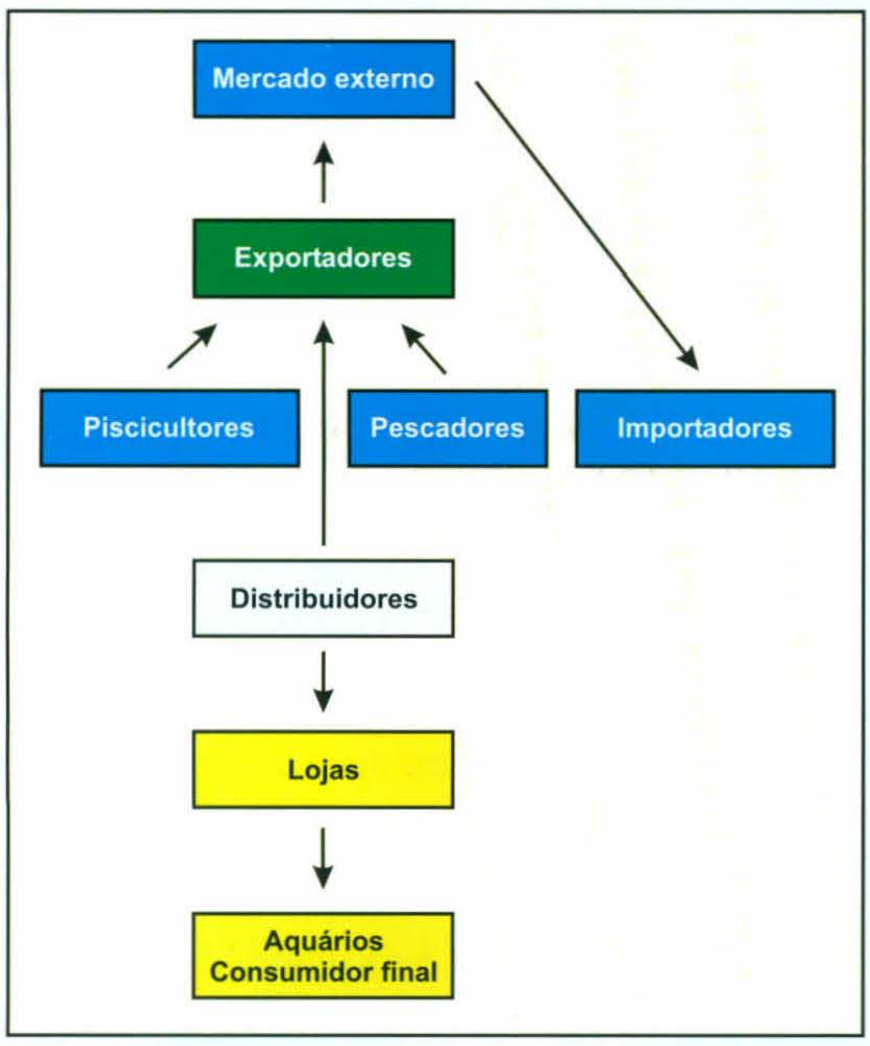

Figura 1 - Organograma representando a dinâmica do comércio de peixes ornamentais

\section{Tipos de Sistemas para Manutenção dos Animais}

\section{Arquitetura dos sistemas}

Nos estabelecimentos de comercialização, os animais são mantidos em sistemas fechados chamados de baterias, onde os aquários podem ou não ter comunicação de água entre si. Geralmente, os sistemas comunicantes são utilizados para o armazenamento de peixes marinhos, e sistemas não comunicantes para os dulcícolas. A comunicação da água entre sistemas fechados oferece vantagens e desvantagens. A vantagem dos sistemas comunicantes está na estabilidade do sistema, pois quanto maior o volume de água mais estável torna-se o sistema no que diz respeito às alterações de $\mathrm{pH}$, temperatura, taxa de oxigênio dissolvido, potencial de oxirredução e denitrificação. A desvantagem desse tipo de sistema está relacionada com o manejo sanitário, pois no caso da ocorrência de doenças, a disseminação do patógeno é facilitada, e quando se torna necessária a desinfecção, os sistemas comunicantes não podem ser isolados (a não ser que sejam projetados para isso); já os sistemas menores e não comunicantes podem ser facilmente manejados.

A escolha de um ou outro sistema irá depender da espécie armazenada, da rotatividade e da densidade de animais mantida em cada sistema. A conseqüência direta do planejamento de sistemas reversíveis (que podem ser isolados, se necessário), se analisada sob o aspecto comercial, é a viabilização da manutenção de estoques pelo estabelecimento, que poderá manter sua atividade mesmo quando há necessidade de algum manejo sanitário.

Do ponto de vista sanitário, é interessante que o estabelecimento possua sistemas reservados e sem peixes, para onde os animais poderão ser remanejados caso seja necessária uma medida de manejo emergencial.

\section{Quanto à natureza dos sistemas}

Os ambientes aquáticos para a manutenção dos animais contidos nesses estabelecimentos podem ser marinhos, dulcícolas ou de água salobra, e os sistemas de natureza dulcícola podem ser ainda de água ácida, neutra ou alcalina.

\section{A Qualidade da Água}

O principal ponto para o sucesso na manutenção de peixes deve-se aos fatores ambientais, em que é fundamental a manutenção da qualidade da água. Isto envolve o conhecimento da sua origem e dos tipos de filtragem utilizados no sistema.

\section{Origem da água}

A água utilizada nos sistemas aquáticos pode ter origem natural (poço ou nascente) ou rede pública e, tratando-se de água salgada, pode ser colhida do 
mar ou preparada com um sal especial para esta finalidade. Vale ressaltar que a água utilizada para a mistura do sal deve ser filtrada por um deionizador ou por filtro para osmose reversa, pois a água oriunda da rede pública normalmente vem acompanhada por resíduos de tratamento e alto teor de fosfatos.

O uso de água natural (doce ou salgada) requer alguns cuidados, pois, dependendo do local da colheita, pode vir contaminada de resíduos químicos (agrotóxicos, metais pesados, amônia, nitrito, nitrato, fosfatos, etc.) ou biológicos, como patógenos, excesso de material orgânico, algas etc.

\section{Conhecimento e monitoramento da qualidade de água}

As alterações dos parâmetros físicos e químicos da água são responsáveis pela maioria das afecções encontradas nesses animais.

Parâmetros físicos: devem ser monitoradas a temperatura e a densidade. Para seu monitoramento, existem ferramentas como o densímetro, o refratômetro; e para temperatura, termômetros digitais, de mercúrio ou de álcool.

Parâmetros químicos: referem-se ao $\mathrm{pH}$, reserva alcalina, nível de amônia, nitrito, nitrato, fosfato, oxigênio dissolvido, sílica e cálcio, (no caso de aquários marinhos). Para isso, existem testes colorimétricos e, especialmente para $\mathrm{pH}$, podem ser utilizados sensores digitais.

\section{Filtragem da água}

O processo de filtragem consiste em eliminar restos de alimentos, fezes e produtos da decomposição de vegetais ou animais mortos, que alteram a qualidade da água e prejudicam os animais contidos no sistema. Por se tratar de sistemas fechados, onde prevalece a recirculação de água, um sistema de filtragem da água é fundamental para o sucesso na manutenção da boa saúde dos animais. Um sistema completo de filtragem deve ser composto de filtragens mecânica, química e biológica.
Mecânica: a filtragem mecânica consiste na captura de grandes ou pequenas partículas não dissolvidas. Para isso, é usada lã de vidro ou perlon, para conter o material particulado em suspensão.

Química: a filtragem química atua removendo moléculas dissolvidas na água pela adsorção, absorção ou trocas iônicas. ${ }^{3}$ Em aquários marinhos, são usados desnatadores ou skimmers, equipamentos que operam por meio da quebra de gorduras. Neles, a espuma de proteína desnatada funciona como um eficiente tipo de filtragem química por adsorção, pois pequenas bolhas de ar trabalham como um substrato filtrante para muitas moléculas orgânicas. A filtragem química por absorção está presente no uso de carvão ativado, enquanto que nas trocas iônicas utilizam-se resinas e outros elementos, como a zeolita, que remove amônia da água doce. ${ }^{3}$

Biológica: a filtragem biológica consiste na transformação de componentes tóxicos gerados em um sistema aquático fechado, por colônias de bactérias nitrificantes que decompõem os resíduos de matéria orgânica em amônia, nitrito e nitrato. Desses elementos, os dois primeiros não devem estar presentes na água, pois são tóxicos aos peixes, enquanto que o nitrato não afeta diretamente a saúde dos animais, exceto quando está presente em altos teores. ${ }^{4}$ Essas colônias de bactérias podem estar presentes principalmente em placas de fundo, bio balls, cascalho e rochas. ${ }^{3}$ As macroalgas também podem ser utilizadas como filtragem biológica, pois durante seu crescimento retiram esses elementos da água.

Esterilização: a esterilização pode ser considerada como um quarto tipo de filtragem, pois remove patógenos do sistema. Para isso, podem ser usados lâmpada ultravioleta e/ou ozonizador. ${ }^{3}$

A luz ultravioleta mostra-se eficiente, pois produz uma energia de ação germicida, eliminando bactérias, fungos, vírus e pequenos protozoários. Esse processo pode ocorrer pela interrupção da química genética desses organismos ou pela criação de oxidantes e outras toxinas na água e ao redor das células. ${ }^{3}$ 
A injeção de ozônio no sistema aumenta o potencial de oxirredução da água e oxida o envoltório de bactérias e vírus e, em protozoários, causa destruição dos cílios. O efeito oxirredutor do ozônio também contribui para clarificar a água por oxidação da matéria orgânica dissolvida e pequenas partículas orgânicas. ${ }^{3} \mathrm{O}$ uso do ozônio deve ser criterioso, pois o ozônio residual pode destruir as delicadas membranas das brânquias dos animais contidos no sistema. ${ }^{3}$ Para controlar a taxa de ozônio residual, existem testes colorimétricos.

\section{Suplementação}

Alguns elementos podem ser adicionados ao sistema para promover o crescimento de determinados organismos, como plantas aquáticas, algas, invertebrados, ou para promover a estabilidade da água, como o tamponador, também conhecido como buffer. A suplementação dependerá da finalidade do aquário, que pode ser destinado à manutenção de plantas, peixes, corais, outros invertebrados etc.

Os suplementos devem ser usados com muito critério, pois seu uso errôneo pode desequilibrar o sistema. Como exemplo, pode-se citar o emprego de compostos orgânicos para alimentação de corais que, se usados em excesso, promoverão um crescimento excessivo de algas e conseqüente alteração de $\mathrm{pH}$ da água.

\section{Entrada de Animais no Estabelecimento}

\section{Origem dos animais}

Os animais comercializados no setor varejista podem ter origem na aqüicultura, na coleta na natureza ou importação (em que podem ser selvagens ou provenientes de aqüicultura). Para o caso de importação, esta atividade deve seguir a Instrução Normativa $n^{\circ} 53$ de 02 de julho de 2003 do MAPA.

Os animais adquiridos devem ser acompanhados de um certificado zoossanitário do país de origem ou de um atestado de saúde para âmbito nacional, representado pela Guia de Trânsito Animal (GTA).

Hoje, vários fatores corroboram contra a garantia do status sanitário dos animais comercializados, como a ausência de profissionais preparados, falta de conhecimento das legislações existentes, pouca organização da atividade ou expectativa de mais lucratividade pelos membros da cadeia. Dessa forma, muitas vezes os peixes chegam ao estabelecimento acometidos de enfermidades, com presença de parasitas ou lesões externas, dificultando o trabalho de manejo dos animais. ${ }^{5}$ Tal fato remete o médico veterinário a ter cautela ao receber ou recomendar ao estabelecimento o recebimento de novas cargas do mesmo fornecedor.

\section{Triagem}

A seleção é uma importante medida profilática na recepção dos animais pelo estabelecimento. Em função do tempo de transporte, alta densidade de animais na mesma embalagem, ausência de jejum para o transporte e brigas, os animais recebidos podem chegar estressados, apresentando alguns sinais clínicos. Estes caracterizam-se por: nado errático, lesões externas, desprendimento excessivo de muco, alteração da coloração, opacidade de córnea, perda de escamas, presença de parasitas que podem se mostrar como pontos pretos ou brancos, ou outros sinais de enfermidades. ${ }^{5}$ Esses animais devem ser separados em outros ambientes para diagnóstico e tratamento antes de serem soltos no sistema principal.

Animais oriundos de importação ou de outras microbacias que não a da região de recebimento deverão ser submetidos à quarentena. ${ }^{6}$

\section{Manejo dos Animais}

No presente artigo, considera-se o manejo como o procedimento que se faz após a triagem ou quarentena dos animais até sua comercialização. Abrange a aclimatação, o acondicionamento e o manejo alimentar. 


\section{Aclimatação}

Para diminuir o estresse e, conseqüentemente, o risco de mortalidade dos animais recém-chegados em virtude de choques de temperatura, $\mathrm{pH}$, densidade da água (no caso de animais marinhos) e intoxicação por amônia, é conveniente realizar a aclimatação dos animais. Nesse procedimento, portanto, devem ser observados os parâmetros acima citados. Em alguns estabelecimentos, utilizam-se caixas plásticas, nas quais os peixes são soltos com a água que os acompanha, e introduz-se, lentamente, a água do sistema nesse ambiente. Essa medida pode minimizar os choques no momento de acondicionar os animais.

A água do transporte nunca deve ser lançada em um sistema de manutenção de animais do estabelecimento. Deverá ser tratada de acordo com a legislação ambiental antes de ser descartada.

A iluminação também é considerada como um fator importante no momento da aclimatação. $\mathrm{O}$ estresse dos animais manuseados pode ser minimizado se for reduzido o estímulo visual, ${ }^{4}$ sendo conveniente realizar o procedimento de aclimatação em caixas escuras ou em ambientes de penumbra.

É importante esclarecer a diferença entre os termos aclimatizar e aclimatar, que são com freqüência utilizados erroneamente por aqueles que trabalham na atividade. Aclimatizar aplica-se quando um organismo se ajusta a certo clima, por exemplo, alterações sazonais entre verão e inverno. Aclimatar ajusta-se a organismos submetidos a uma condição imposta artificialmente, ${ }^{7}$ como a introdução de um peixe em um aquário. Neste caso, o correto é a aplicação do termo aclimatar.

\section{Acondicionamento dos animais}

No acondicionamento dos animais, dois fatores devem ser observados: compatibilidade e densidade.

Quanto ao primeiro, deve-se respeitar as diferentes compatibilidades entre as espécies de animais (peixes e invertebrados) mantidos em um sistema fechado. Entre as espécies dulcícolas e marinhas, existem espécies territorialistas, pacíficas, carnívoras etc. Como exemplo, o peixe leão ou lion (Pterois spp) é um peixe marinho estritamente carnívoro. Na água doce, machos do peixe betta (Betta splendens) devem ser mantidos isolados devido à sua agressividade. Uma das causas de lesões nos animais em um sistema fechado ocorre em função de agressões mútuas (brigas), em que muitas vezes grandes fragmentos de nadadeiras ou mesmo pele e escamas são arrancados. Estas lesões podem funcionar como porta de entrada para bacterioses, micoses, viroses ou doenças parasitárias.

A densidade de animais, quando alta, pode causar estresse, favorecendo o aparecimento de enfermidades. Poderá variar quanto às espécies armazenadas. No entanto, o importante é manter o bom senso e não superlotar os compartimentos.

\section{Manejo alimentar}

A alimentação pode ser feita com rações industrializadas ou alimentos naturais. Deve ser diária e deve-se ter cautela para não superalimentar os animais, o que acarreta poluição do sistema. É importante seguir, sempre que possível, os requerimentos nutricionais de cada espécie, e para aquelas ornamentais, a atividade ainda carece de estudos. Além disso, há espécies que dificilmente se adaptam à alimentação com rações comerciais, necessitando que sejam oferecidos alimentos vivos, como Artemia sp, peixes menores, moluscos, vermes e vegetais para sua manutenção em cativeiro. Acreditamos que esse é um obstáculo a ser superado pela atividade de aqüicultura (marinha e dulcícola).

Existem diversas marcas de rações comercias, mas devem ser recomendadas apenas aquelas devidamente registradas no MAPA, pois assim o profissional pode indicar o consumo de um produto seguro e, indiretamente, contribuir para a regulamentação dos insumos. 


\section{Invertebrados}

Nessa atividade, o colega também irá se deparar com algumas classes de invertebrados, como moluscos (caracóis, lesmas do mar, polvos, bivalves), equinodermos (estrelas, ouriços, pepinos do mar, ofiuros) e celenterados (anêmonas e corais). ${ }^{2}$

É importante saber que esses animais muitas vezes não são compatíveis com os peixes e entre si. As anêmonas, por exemplo, não devem ser armazenadas com peixes, pois, sendo carnívoras, podem ingerir um peixe debilitado (exceção para os peixes palhaço, gênero Amphiprion, que podem viver em simbiose com as anêmonas). Alguns peixes também alimentam-se de corais, o que torna inviável armazená-los junto, pois ambos possuem valor comercial.

Em relação a comportamentos, compatibilidades, ecologia e outras informações pertinentes à manutenção desses animais em ambientes fechados, o profissional poderá encontrar literatura especializada. Porém, quanto aos aspectos nutricionais e patológicos, estes ainda carecem de estudo. ${ }^{1}$

\section{Principais Doenças Transmissíveis}

As doenças que podem afetar os peixes ornamentais são causadas por protozoários, fungos, bactérias, helmintos, crustáceos e vírus. Entre os protozoários, destacam-se parasitos do gênero Ichthyophthirius, Cryptocaryon, Amyloodinium, Oodinium, Chilodonella, Brooklynella, Hexamita, Cryptobia e trichodinídeos. Já no grupo dos helmintos, os mais comumente diagnosticados são os trematodas monogenéticos Dactylogirídeos, Gyrodactilideos e nematodas ${ }^{8}$ (Camallanus). Os crustáceos são representados pela Lernaea, Ergasilus e Argulus. Uma grande quantidade de bactérias pode afetar os peixes, sendo a maioria delas, Gram-negativas. ${ }^{2}$ Poucas espécies Gram-positivas afetam os peixes. ${ }^{2}$ Quanto aos vírus, por ainda não ser possível um diagnóstico no Brasil, atualmente, qualquer comentário sobre a ocorrência fica prejudicado.
Este assunto, bastante amplo, será motivo de um próximo trabalho, em que serão abordados patologia, epidemiologia, tratamento e profilaxia.

\section{Profilaxia}

\section{Higiene das instalações}

A manutenção da limpeza dos aquários ou baterias consiste nos seguintes procedimentos: sifonagem periódica dos aquários, dos reservatórios de água e dos decantadores evitando-se a acumulação de resíduos; retirada de algas que crescem nos vidros, canos, bombas; limpeza periódica de bombas principalmente no caso de aquários marinhos, em que a precipitação de cálcio pode travar esses equipamentos - e sensores, se presentes. ${ }^{2}$

A limpeza externa dos aquários é fundamental para a perfeita observação dos animais pelos funcionários e pelo público. Vidros com água escorrida causam má impressão, por melhor que esteja a qualidade da água para a manutenção dos animais.

O piso deve estar sempre limpo e seco, pois também afeta a percepção de limpeza de quem entra no estabelecimento, além de evitar que as pessoas escorreguem e se machuquem.

Peixes mortos devem ser imediatamente retirados dos aquários, pois podem representar uma via de transmissão de doenças. Os produtos de sua decomposição também podem afetar a qualidade da água, além de prejudicar o aspecto estético dos sistemas. Portanto, devem ser descartados em lixo séptico.

\section{Higiene dos utensílios}

Esta é uma parte delicada dentro do assunto profilaxia. Neste caso, alguns hábitos adquiridos no exercício da atividade podem afetar diretamente a saúde dos animais. Então, pouco a pouco, devese transmitir os hábitos corretos para o manejo dos animais. Para sistemas aquáticos não comuni- 
cantes, os utensílios como canecas, redes e mangueiras devem ser específicos para cada sistema, por serem importantes fômites. Além disso, devem ser mantidos, após cada utilização, numa solução de formol ou amônia quaternária. Essa medida deve ser administrada com muito cuidado, pois esses utensílios têm de ser muito bem enxaguados antes de serem novamente utilizados. As bombas também podem atuar como fômites e devem ter o mesmo tratamento citado acima. ${ }^{2}$

\section{Treinamento de pessoal}

As maiores dificuldades que deverão ser superadas são a transmissão de conceitos sanitários, a conscientização para adoção de medidas higiênicas e profiláticas e a correção de vícios adquiridos durante o exercício da atividade.

Para superar esses inconvenientes, os funcionários, principalmente aqueles que trabalham diretamente com os animais, devem ser incentivados e capacitados por intermédio de palestras e cursos que podem ser administrados no estabelecimento ou em outro local.

\section{Segurança dos Funcionários}

\section{Zoonoses}

Apesar de esses animais não terem como destino a alimentação humana (e, neste caso, podese citar principalmente a ocorrência de zoonoses parasitárias), ${ }^{9}$ algumas bactérias que causariam doenças em peixes - ou apenas seriam veiculadas por estes - podem ser a causa de doenças no homem também. A infecção por esses agentes está relacionada à presença de feridas na pele e contato do homem durante a manipulação de água ou peixe infectado.

O desenvolvimento de doenças em humanos requer um comprometimento do sistema imunológico e, muitas delas, estão relacionadas à síndrome de imunodeficiência adquirida (AIDS). ${ }^{4}$ Existem referências de infecção por Streptococcus, Erysipelothrix rhusiopathiae, Mycobacterium marinum, M. fortuitum, Nocardia asteróides, $N$. kampachi, Vibrio, Plesiomonas, Aeromonas hydrophila, Pseudomonas e Enterobactérias (Escherichia, Salmonella, Klebsiella, Edwardsiella, Yersinia).

\section{Animais venenosos}

O estudo dos acidentes provocados por animais aquáticos em seres humanos tem merecido a atenção de vários pesquisadores. ${ }^{10}$ Os animais aquáticos capazes de provocar acidentes em seres humanos, em função da frequiência e gravidade dos acidentes, são: poríferos, celenterados, vermes, moluscos, eqüinodermos, peixes e répteis. A ação dos venenos varia, mas os principais efeitos são neurotóxicos, proteolíticos, miotóxicos, hemotóxicos e citotóxicos. ${ }^{10}$

Para peixes marinhos ou dulcícolas, o perigo consiste em glândulas produtoras de veneno localizadas em ferrões que podem estar presentes nos seguintes locais: ${ }^{10}$

- cauda: arraias das famílias Dasyatididae e Myliobatididae;

- nadadeiras dorsais: peixe-leão (Pterois spp), peixepedra (Synanceja spp), peixe-escorpião (família Scorpaenidae), bagres, cação-bagre (Squalus spp);

- inserção das nadadeiras dorsais: peixes-cirurgiões;

- nadadeiras laterais: bagres e cascudos;

- mordidas: moréias, pequenos tubarões.

É importante destacar que os venenos permanecem ativos durante 24 horas após a morte do peixe. ${ }^{10}$

Os invertebrados também podem ser perigosos quando manipulados incorretamente (sem luvas ou redes) nas seguintes situações: ${ }^{10}$

- anêmonas e alguns corais: pela ação de nematocistos, que em contato com a pele pode causar dor intensa, com possibilidade de ocorrer erupção papuloeritematosa, urticariforme, vesículas, bolhas, necrose superficial e reações alérgicas, como angioedema e choque anafilático; 
- ouriços: por suas espículas ocas em sua superfície, podem causar sérios acidentes traumáticos e servir de porta de entrada para infecções secundárias, incluindo infecção tetânica. Algumas espécies possuem veneno com efeito hipotensor, hemolítico, cardiotóxico e neurotóxico por toxinas presentes nas pedicelárias (pequenos tentáculos presentes entre as espinhas);

- estrelas do mar: a espécie Acanthaster planci (conhecida como coroa de espinhos), a única venenosa, causa edema e necrose cutânea;

- pepinos do mar: produzem holoturina, substância irritante da pele e das mucosas;

- polvos: a espécie Hapalochlaena spp (polvo dos anéis azuis) inocula veneno contido nas glândulas salivares por um bico córneo, podendo causar paralisia neuromuscular e até óbito por insuficiência respiratória;

- crustáceos: não produzem venenos, mas podem provocar traumatismos com laceração, que podem servir de porta de entrada para outras infecções, e reações alérgicas por substâncias presentes em seu corpo;

- qualquer substrato que acompanhe os corais pode possuir em sua base alguns vermes que possuem espículas que penetram na epiderme das mãos causando processos irritativos e dermatites, com quadro de edema, pápulas, dor e prurido.

Para evitar acidentes, é adequado o uso de luvas e redes para manipulação dos animais.

\section{Monitoramento de equipamentos e instalações elétricas}

Quando se trabalha em ambiente úmido, as instalações de energia ficam mais susceptíveis à oxidação, principalmente quando se tratam de sistemas de água salgada. Se não houver manutenção adequada, podem ocorrer acidentes como choques elétricos nos funcionários ou curto-circuitos na rede elétrica interna. No segundo caso, se não houver nenhuma pessoa para observar o problema no momento, como durante a noite ou feriados, os prejuízos podem ser grandes com o desligamento dos equipamentos elétricos (resfriadores, aquecedores e bombas de circulação). ${ }^{2}$
Nesse tipo de estabelecimento, devem ser observados periodicamente alguns pontos críticos como: tomadas, plugs, reatores de iluminação, sensores eletrônicos, resfriadores, aquecedores, emendas na fiação e caixa elétrica. ${ }^{2}$

Pode ser mais seguro, em grandes sistemas, utilizar disjuntores individuais para equipamentos de maior potência (bombas, aquecedores, resfriadores). Esse procedimento evita, em casos de problemas no fornecimento de energia elétrica, que todos os equipamentos parem de funcionar concomitantemente.

\section{Conclusões: o futuro da atividade}

Como foi dito, a atividade de comercialização de peixes ornamentais é relativamente bem-sucedida, mas carece de medidas sanitárias e acompanhamento técnico adequado. No Brasil, em função da abundância de recursos aquáticos, é uma atividade em que há muito campo para desenvolvimento. Todavia, seu futuro reside na aqüicultura, visto que os estoques naturais tendem a se esgotar. Essa constatação está diretamente relacionada com o preparo de profissionais para atuar nesta área, que dinamizará e consolidará a atividade.

Hoje a maior parte dos animais (importados e nativos) comercializados é proveniente de captura. Para inverter este quadro, é preciso que o mercado seja abastecido por peixes provenientes de aqüicultura. Assim, é necessário que a fisiologia da reprodução de várias espécies marinhas e dulcícolas seja estudada no Brasil e em outros países, o que já ocorre, contudo, de forma ainda tímida.

\section{Agradecimentos}

À médica veterinária Dra. Maria Paula Martinez Okumura e ao zootecnista Sr. Mauricio Nagata pela contribuição como revisores deste trabalho. 


\section{Abstract}

The purpose of this article is to inform the veterinarian about dealing with management and trading of ornamental fish, an often neglected subject in Veterinary Medicine Schools and post-graduation courses. Ornamental fish trading is a well-established activity in Brazil, but it lacks professionals addressing matters such as prophylactic management, pathology, diagnosis and treatment. Also, it includes new concepts for the veterinarian, such as the ones represented by the physical and chemical properties of water. The article briefly addresses the most important points of this activity that should be considered from a veterinary medical standpoint.

Keywords: Ornamental fishes. Commerce, organization and administration. Aquatic environment, closed. Veterinarians.

\section{Resumen}

Este trabajo tiene como propósito el de presentar consideraciones importantes para los veterinarios sobre el comercio y cuidado de peces ornamentales, que es un área de actuación poco abordada por las Facultades de Medicina Veterinaria y cursos de posgrado. El comercio de peces ornamentales es una actividad bien establecida en Brasil, sin embargo carece de profesionales que actúan en asuntos como medidas profilácticas, patología, diagnosis y tratamiento. También incluye nuevos conceptos para el veterinario, como las características físicas y químicas del agua. El artículo aborda de manera sucinta, los principales puntos de esa actividad que deben ser observados desde la óptica de la Medicina Veterinaria.

Palabras-clave: Peces ornamentales. Comercio, organización y administración. Ambiente acuático cerrado. Veterinarios.

\section{Referências}

1. ALEXANDRINO, A. C. Empreendimentos piscícolas e o médico veterinário. Revista de Educação Continuada do CRMV-SP, v. 2, p. 43-65, 1999.

2. ARAUJO, A. P. Controle de sistemas aquáticos fechados para manutenção de peixes ornamentais marinhos pelo médico veterinário. In: CONGRESSO BRASILEIRO DE MEDICINA VETERINÁRIA CONBRAVET, 30., 2003, Manaus. Anais... Brasília, Sociedade Brasileira de Medicina Veterinária, 2003. p.100-101.

3. MOE, M. A. The marine aquarium reference: systems and invertebrates. Plantation: Green Turtle Publications, 1993. 509 p.
4. STOSKOPF, M. K. Fish medicine. Philadelphia: Saunders, 1993. 882 p.

5. ARAUJO, A. P.; ALEXANDRINO, A. C. Alguns aspectos sanitários da importação de animais aquáticos marinhos. In: CONGRESSO BRASILEIRO DE MEDICINA VETERINÁRIA - CONBRAVET, 30., 2003, Manaus. Anais... Brasília, Sociedade Brasileira de Medicina Veterinária, 2003. p.102.

6. ALEXANDRINO, A. C. Manual de prevenção de doenças em pisciculturas. Boletim Técnico do Instituto de Pesca, São Paulo, n. 23, p. 1-45, 1998.

7. NIELSEN, K. S. Fisiologia animal: adaptação e meio ambiente. 5. ed. Cambridge: Cambridge University Press, 2002. 611 p. 
8. EIRAS, J.C. Elementos de ictioparasitologia. Porto: Fundação Eng. Antônio de Almeida, 1994. 339 p.

9. OKUMURA, M. P. M.; ALEXANDRINO, A. C.; ESPÍNDOLA FILHO, A. Principais zoonoses transmitidas por pescados: revisão. Revista de Educação Continuada do CRMV-SP, v. 2, p. 66-80, 1999.

10. HADDAD JR., V. Atlas de animais aquáticos perigosos do Brasil: guia médico de diagnóstico e tratamento de acidentes. São Paulo: Roca, 2000. 145 p.

\section{Literatura recomendada}

AMLACHER, E. Manual de enfermidades de los peces. Zaragoza: Acribia, 1964. 319 p.

BUTCHER, R. L. Manual of ornamental fish. Quedgeley: British Small Animal Veterinary Association, 1996. $200 \mathrm{p}$.
CARNEVIA, D. Enfermedades de los peces ornamentales. Buenos Aires: Agro-Vet, 1993. 319 p.

KINKELIN, P.; MICHEL, C.; GUITTINO, P. Tratado de las enfermedades de los peces. Zaragoza: Acribia, 1991. $353 \mathrm{p}$.

NOGA, E. J. Fish disease. Saint Louis: Mosby-Year Book, 1995. 367 p.

OFFICE INTERNATIONAL DES EPIZOOTIES. Código Sanitário Internacional para Organismos Aquáticos. Paris: World Organization for Animal Health, 2003.

OFFICE INTERNATIONAL DES EPIZOOTIES. Diagnostic Manual for Aquatic Animal Diseases, Paris: World Organization for Animal Health, 2003.

REINCHENBACH-KLINKE, H. H. Enfermedades de los peces. Zaragoza: Acribia, 1982. 507 p. 